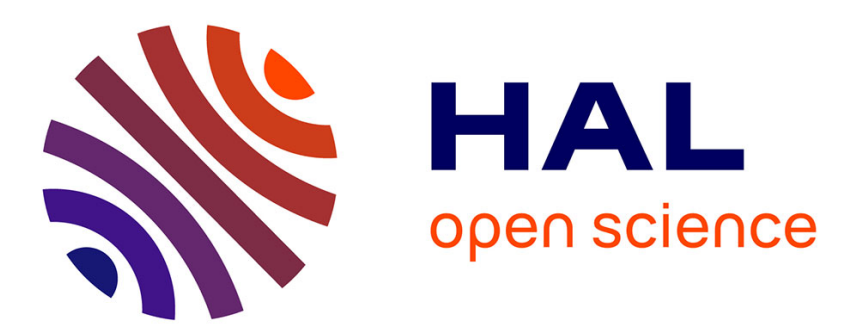

\title{
Comparative study of metallic silicide-germanide orthorhombic MnP systems
}

Damien Connétable, Olivier Thomas

\section{To cite this version:}

Damien Connétable, Olivier Thomas. Comparative study of metallic silicide-germanide orthorhombic MnP systems. Journal of Physics: Condensed Matter, 2013, vol. 25 (n 35), pp. 1-6. 10.1088/09538984/25/35/355403. hal-01166362

\section{HAL Id: hal-01166362 \\ https://hal.science/hal-01166362}

Submitted on 22 Jun 2015

HAL is a multi-disciplinary open access archive for the deposit and dissemination of scientific research documents, whether they are published or not. The documents may come from teaching and research institutions in France or abroad, or from public or private research centers.
L'archive ouverte pluridisciplinaire HAL, est destinée au dépôt et à la diffusion de documents scientifiques de niveau recherche, publiés ou non, émanant des établissements d'enseignement et de recherche français ou étrangers, des laboratoires publics ou privés. 


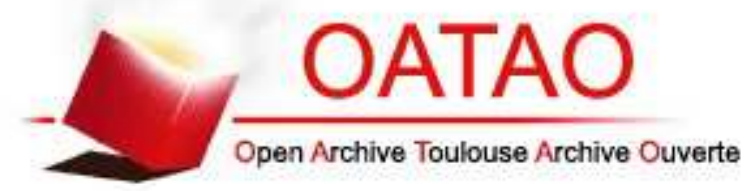

\section{Open Archive TOULOUSE Archive Ouverte (OATAO)}

OATAO is an open access repository that collects the work of Toulouse researchers and makes it freely available over the web where possible.

This is an author-deposited version published in : http://oatao.univ-toulouse.fr/ Eprints ID : 13983

To link to this article : doi: $10.1088 / 0953-8984 / 25 / 35 / 355403$

URL : http://dx.doi.org/10.1088/0953-8984/25/35/355403

To cite this version : Connétable, Damien and Thomas, Olivier

Comparative study of metallic silicide-germanide orthorhombic MnP systems. (2013) Journal of Physics: Condensed Matter, vol. 25 ( $\left.\mathrm{n}^{\circ} 35\right)$. pp. 1-6. ISSN 0953-8984

Any correspondance concerning this service should be sent to the repository administrator: staff-oatao@ listes-diff.inp-toulouse.fr 


\title{
Comparative study of metallic silicide- germanide orthorhombic MnP systems
}

\author{
Damien Connétable $^{1}$ and Olivier Thomas ${ }^{2}$ \\ ${ }^{1}$ CIRIMAT, CNRS-INP-UPS UMR 5085, École Nationale d'Ingénieurs en Arts Chimiques et \\ Technologiques (ENSIACET) 4, allée Émile Monso, BP 44362, F-31030 Toulouse Cedex 4, France \\ ${ }^{2}$ Aix-Marseille Université, CNRS, IM2NP, UMR 7334, Campus de St Jérome, F-13397 Marseille \\ Cedex, France
}

E-mail: damien.connetable@ensiacet.fr

\begin{abstract}
We present a comparative study of the structural, energetic, electronic and elastic properties of MX type MnP systems (where $\mathrm{X}=\mathrm{Si}$ or $\mathrm{Ge}$, and $\mathrm{M}=\mathrm{Pt}$, $\mathrm{Pd}$ or $\mathrm{Ni}$ ) using first-principles calculations. The optimized ground state properties of these systems are in excellent agreement with the experimental values. A detailed comparative study of the elastic properties of polycrystalline structures is also presented. We analyze the relationship between the composition and the properties of the systems. Finally, we present the properties of $\mathrm{NiSi}_{1-x} \mathrm{Ge}_{x}$ alloys. We show that these properties depend linearly on the Ge content of the alloy. This work has important consequences for semiconductor devices in which silicides, germanides and alloys thereof are used as contact materials.
\end{abstract}

\section{Introduction}

Transition metal silicides are important contact materials for advanced field effect microelectronic devices. These materials are significant because of their metallic character and compatibility with silicon. More recently, SiGe alloys have been used to increase the mobility of charge carriers [1] or as sources of stresses in silicon channels, which also increase the mobility of the charge carriers [2]. Germanium or silicon-germanium alloys are contacted by forming transition metal germanides or silico-germanides. Most transition metals form isotopic silicides and germanides as full or extended solid solutions. In this study we focus on MX silicides or germanides (where $\mathbf{M}=$ transition metal and $\mathrm{X}=\mathrm{Si}$ or $\mathrm{Ge}$ ) that crystallize into orthorhombic MnP type structures. This behavior is especially observed for NiSi and $\mathrm{NiGe}$, which are intermetallics that are currently used for contacting advanced electronic devices.

The NiSi structure has been studied at ambient pressure [3] and high pressures [4]; however, the effects of varying the composition (of the metal and/or the $\mathrm{Si}$ atoms) have not been investigated. The purpose of this study is to investigate the elastic properties of the MX-MnP systems and how the metal and/or $\mathrm{Si} / \mathrm{Ge}$ affects these properties.

In section 2, we present the computational details for this study. The ground state properties (i.e., the lattice parameters, the formation energies and the electronic properties) of each alloy are presented and compared to each other in sections 3 and 4 . In section 5, the elastic properties (mono- and polycrystalline) of all of the MX phases are presented. The anisotropies of these phases are then presented and compared with each other. We conclude in section 6 with a discussion on the energetic and elastic properties of $\mathrm{NiSi}_{1-x} \mathrm{Ge}_{x}$ alloys.

\section{Computational details}

The ground states of MX-MnP and the reference states (fcc and diamond phases) have been optimized by implementing DFT VASP [5]. Projected augmented wave pseudopotentials [6] were used. The spin-polarized version of the Perdew-Burke-Ernzerhof [7] (PBE) generalized gradient approximation (GGA) was used for the exchange-correlation functional. The structures were optimized by sampling the Brillouin zones using $\Gamma$-centered $25 \times 25 \times 25$ and 


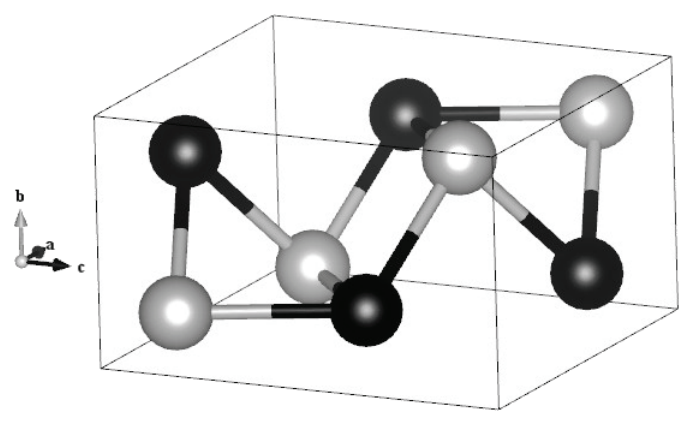

Figure 1. Schematic of the MnP structure: the metal atoms are shown in gray and the $\mathrm{Ge} / \mathrm{Si}$ atoms are shown in black.

Table 1. Ground state properties of the reference states: lattice parameters $\left(a_{o}\right.$, in $\AA$ ) , cohesive energies $\left(E_{\text {coh }}\right.$, in $\mathrm{eV} /$ atom $)$, magnetic moments ( $\mu_{\mathrm{B}}$, measured in Bohr units) and bulk modulus $\left(B_{o}\right.$, in GPa); experimental data (from Kittel [9]) are provided for comparison.

\begin{tabular}{lllllll}
\hline & & & $a_{o}$ & $E_{\text {coh }}$ & $\mu_{\mathrm{B}}$ & $B_{o}$ \\
\hline $\mathrm{Ni}$ & fcc & Theo. & 3.52 & 4.76 & 0.62 & 198 \\
& & Exp. & 3.52 & 4.44 & 0.62 & 186 \\
$\mathrm{Pd}$ & fcc & Theo. & 3.96 & 3.71 & 0.33 & 163 \\
& & Exp. & 3.89 & 3.89 & 0.0 & 181 \\
$\mathrm{Pt}$ & \multirow{2}{*}{ fcc } & Theo. & 3.97 & 5.45 & 0.0 & 251 \\
& & Exp. & 3.92 & 5.84 & 0.0 & 278 \\
\hline \multirow{2}{*}{$\mathrm{Si}$} & \multirow{2}{*}{ diam } & Theo. & 5.47 & 4.56 & 0.0 & 90 \\
& & Exp. & 5.43 & 4.63 & 0.0 & 99 \\
$\mathrm{Ge}$ & \multirow{2}{*}{ diam } & Theo. & 5.77 & 3.74 & 0.0 & 57 \\
& & Exp. & 5.68 & 3.85 & 0.0 & 77 \\
\hline
\end{tabular}

$15 \times 25 \times 15$ Monkhorst and Pack grids [8] for the fcc and diamond systems and the MnP structures, respectively. Cut-off energies of $600 \mathrm{eV}$ were used. We adopted the finest tetrahedron of $20 \times 30 \times 20$ grids to calculate the electronic density of states (eDOS) and the formation energies for $\mathrm{MnP}$ systems.

The pseudo-potentials were tested on the reference phases. Table 1 shows that the lattice parameters, the cohesive energies, the magnetism and the bulk modulus are in good agreement with the experimental and theoretical literature. Two cases should be noted: Ge and Pd. We obtain a 'large' lattice parameter for germanium, which results in a softer bulk modulus than the experimental result. Our results for fcc-Pd are in agreement with previous theoretical work [10] on magnetism. We assumed that magnetic properties of the $\mathrm{Pd}$ alloys were not related to the results for fcc-Pd. All of the alloys were found to be non-magnetic.

\section{Structural properties}

The MX intermetallics, where $\mathrm{M}=\mathrm{Ni}$, $\mathrm{Pt}$ or $\mathrm{Pd}$, and $\mathrm{X}=\mathrm{Si}$ or Ge, crystallize in the MnP orthorhombic structure (space group 62, Pnma- $\left.\mathrm{D}_{2 \mathrm{~h}}^{16}, \mathrm{~B} 31\right)$. The primitive cell is composed of eight atoms (oP8), where both atoms ( $\mathrm{M}$ and $\mathrm{X})$ are located in $4 \mathrm{c}$ Wyckoff positions $\left(u_{x}, 1 / 4, u_{z}\right)$. Figure 1 is a schematic of the MnP structure.

Table 2 provides the optimized atomic positions which are weakly dependent on the compositions (of $\mathrm{M}$ and $\mathrm{X}$ ).
Table 2. Wyckoff data for MnP systems, showing atoms in the $4 \mathrm{c}$ position $\left(u_{x}, 1 / 4, u_{z}\right)$.

\begin{tabular}{|c|c|c|c|c|}
\hline & & & $u_{x}$ & $u_{z}$ \\
\hline \multirow[t]{2}{*}{$\mathrm{NiSi}$} & [3] & $\mathrm{Ni}$ & 0.0085 & 0.1889 \\
\hline & & $\mathrm{Si}$ & 0.1795 & 0.5843 \\
\hline \multirow[t]{2}{*}{ PdSi } & & $\mathrm{Pd}$ & 0.0039 & 0.1912 \\
\hline & & $\mathrm{Si}$ & 0.1771 & 0.5732 \\
\hline \multirow[t]{2}{*}{ PtSi } & & $\mathrm{Pt}$ & 0.9964 & 0.1941 \\
\hline & & $\mathrm{Si}$ & 0.1791 & 0.5825 \\
\hline \multirow[t]{2}{*}{$\mathrm{NiGe}$} & & $\mathrm{Ni}$ & 0.0058 & 0.1908 \\
\hline & & $\mathrm{Ge}$ & 0.1905 & 0.5855 \\
\hline \multirow[t]{2}{*}{ PdGe } & & $\mathrm{Pd}$ & 0.0040 & 0.1907 \\
\hline & & $\mathrm{Ge}$ & 0.1859 & 0.5766 \\
\hline \multirow[t]{2}{*}{ PtGe } & & $\mathrm{Pt}$ & 0.9996 & 0.1925 \\
\hline & & $\mathrm{Ge}$ & 0.1859 & 0.5865 \\
\hline
\end{tabular}

Table 3. Lattice parameters (in $\AA$ ) and formation energies (in $\mathrm{meV} / \mathrm{atom}$ ) for MnP systems compared to experimental data.

\begin{tabular}{llllc}
\hline & $a_{o}$ & $b_{o}$ & $c_{o}$ & $E_{\mathrm{f}}$ \\
\hline $\mathrm{NiSi}$ & $5.179^{\mathrm{a}}$ & $3.365^{\mathrm{a}}$ & $5.613^{\mathrm{a}}$ & $-496^{\mathrm{a}}$ \\
& $5.15^{\mathrm{b}}$ & $3.35^{\mathrm{b}}$ & $5.60^{\mathrm{b}}$ & \\
$\mathrm{PdSi}$ & 5.638 & 3.469 & 6.177 & -537 \\
& $5.65^{\mathrm{b}}$ & $3.40^{\mathrm{b}}$ & $6.15^{\mathrm{b}}$ & \\
$\mathrm{PtSi}$ & 5.663 & 3.629 & 5.998 & -671 \\
& $5.600^{\mathrm{c}}$ & $3.584^{\mathrm{c}}$ & $5.924^{\mathrm{c}}$ & $-670^{\mathrm{c}}$ \\
& $5.61^{\mathrm{b}}$ & $3.60^{\mathrm{b}}$ & $5.95^{\mathrm{b}}$ & $-620^{\mathrm{d}}$ \\
\hline $\mathrm{NiGe}$ & 5.419 & 3.464 & 5.864 & -313 \\
& $5.40^{\mathrm{b}}$ & $3.45^{\mathrm{b}}$ & $5.85^{\mathrm{b}}$ & \\
$\mathrm{PdGe}$ & 5.970 & 3.565 & 6.367 & -458 \\
& $5.80^{\mathrm{b}}$ & $3.50^{\mathrm{b}}$ & $6.36^{\mathrm{b}}$ & \\
PtGe & 5.842 & 3.743 & 6.187 & -475 \\
& $5.75^{\mathrm{b}}$ & $3.72^{\mathrm{b}}$ & $6.11^{\mathrm{b}}$ & \\
\hline a Theo. PBE [3]. ${ }^{\mathrm{b}}$ Exp. [11]. ${ }^{\mathrm{c}}$ Theo. LDA [12]. \\
d Exp. [13].
\end{tabular}

Table 3 shows that the optimized lattice parameters, in contrast, depend strongly on the species. The lattice parameters are in excellent agreement with the low temperature experimental data [11]. In all of the cases, the GGA simulations produce slightly higher lattice parameters than the experimental results, unlike the results obtained using LDA functionals. For PtSi, Beckstein et al [12] found lattice parameters smaller than those reported here or those obtained from experimental measurements. These differences lead to significant changes in the $\mathrm{PtSi}$ properties and the elastic properties in particular (see below).

Comparing the results for all of the systems shows that the lattice parameters of each phase are highly dependent on the phase composition. Steric effects may be used to explain the primary changes in the lattice parameters of the $\mathrm{MGe} / \mathrm{Si}$ systems. We illustrate this result by evaluating the relative decrease in the lattice parameters between $\mathrm{Si}$ and $\mathrm{Ge}$ $(a(\mathrm{Si}) / a(\mathrm{Ge}))$ for each of the three metals. For all of the systems, we find a ratio of approximately 0.97 between $\mathrm{Si}$ and $\mathrm{Ge}$, which is equivalent to the one found for the $\mathrm{Si} / \mathrm{Ge}$ diamond structure.

We also find that all of the phases are highly stable with respect to their reference states: the stability increases with 


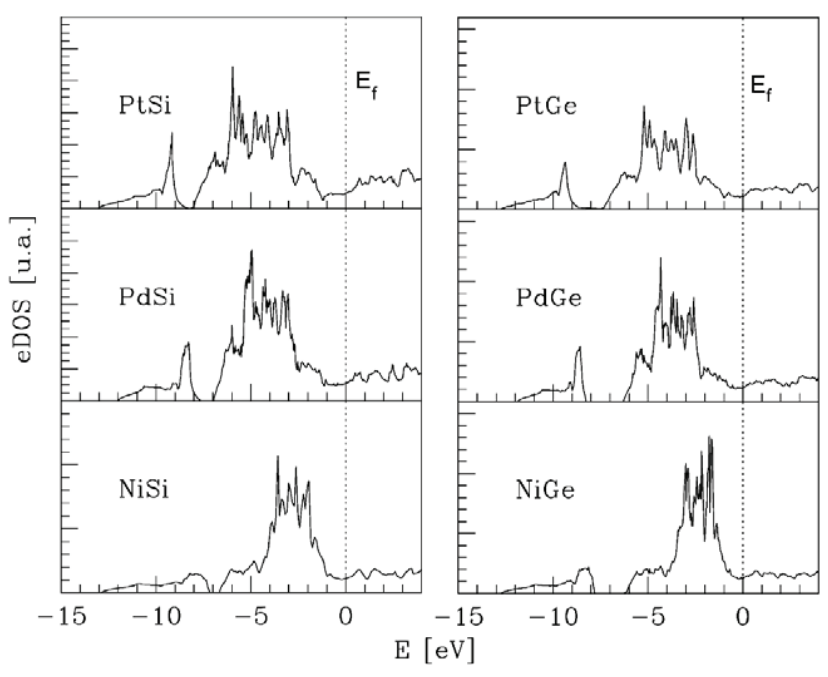

Figure 2. Electronic density of states of MX-MnP; the NiSi values are plotted from the results in [3].

Table 4. Density of states at the Fermi level $\left(N\left(E_{\mathrm{f}}\right)\right.$, in states $\left.\mathrm{eV}^{-1}\right)$ for different elements.

\begin{tabular}{llll}
\hline $\mathrm{X} \backslash \mathrm{M}$ & $\mathrm{Ni}$ & $\mathrm{Pd}$ & $\mathrm{Pt}$ \\
\hline $\mathrm{Si}$ & 2.20 & 2.16 & 1.99 \\
$\mathrm{Ge}$ & 2.44 & 2.24 & 2.19 \\
\hline
\end{tabular}

the weight of the metal atom. All of the structures are metallic (see the electronic properties given above) and non-magnetic.

\section{Electronic properties}

Figure 2 shows the electronic density of states (eDOS). Note that all of the eDOSs are extremely similar, especially for the same metal, suggesting that the metal controls the electronic properties.

We analyze each system more precisely by projecting the density of states (pDOS) onto the orbitals (not shown here). The pDOSs are extremely similar to those reported for NiSi in [3]. At low energies, we find the M and X s shells; near the Fermi level, the $\mathrm{p}$ shells of $\mathrm{X}$ and $\mathrm{d}$ orbitals of the metals are hybridized. The $\mathrm{p}$ and s shells of the Ge systems are slightly more contracted, thereby inducing a larger gap in the valence bands. At the Fermi level, the density of states is always localized near a minimum. Table 4 shows the density of states at the Fermi level $\left(N\left(E_{\mathrm{f}}\right)\right)$ for reference. For all of the systems, $N\left(E_{\mathrm{f}}\right)$ is approximately 2 states $\mathrm{eV}^{-1}$ and is approximately $10 \%$ larger for $\mathrm{Ge}$ systems than for $\mathrm{Si}$ systems.

\section{Elastic properties}

The elastic constants were calculated using the same methodology as the one presented in [3]. The elastic properties of orthorhombic systems are characterized by nine elastic constants, corresponding to the six diagonal terms $\left(C_{i i}\right.$, where $i=1, \ldots, 6)$ and three off-diagonal terms $\left(C_{12}, C_{13}\right.$ and $C_{23}$ ). The elastic constants and the bulk modulus are listed in table 5 .

The elastic constants of the Pd alloys are smoother (by $10-15 \%$ ) than those for $\mathrm{Ni}$ and $\mathrm{Pt}$ systems (as for the reference states). The elastic constants for the Ge alloys are also approximately $20 \%$ smoother than those for Si systems. This evolution can be related to the decrease in the lattice parameters across the systems.

Our results for $\mathrm{PtSi}$ are clearly different from those reported by Beckstein [12], i.e., our results are $10 \%$ smaller than Beckstein's results. This difference can be attributed to two main effects: the differences between the lattice parameters and overestimates of the binding energy, i.e., bonds are stronger within the LDA.

We deduce the mono- and polycrystalline elastic properties of the system from these data and analyze the anisotropies. Following [3], we compute the elastic properties of the polycrystalline structures: the shear and bulk moduli $(G$ and $B)$ using the Voigt, Reuss and Hill approximations, Young's modulus (Y), Poisson's ratio (v), and the bulk modulus along different axes. The results are summarized in table 6.

Note that the 'average' mechanical properties, i.e., v, $G$ and $B$, depend weakly on the alloy composition. In contrast, and as reported in our results for the lattice parameters, the bulk modulus along the crystallographic axes and the Young's modulus are strongly anisotropic. This anisotropy is illustrated in figure 3. The anisotropic values are given in table 7. The anisotropy decreases when going from $\mathrm{Ni}$ to Pt (see table 8). Germanides are softer than silicides, which is consistent with the lower melting points of germanides relative to silicides. However, germanides exhibit a slightly more pronounced anisotropy than silicides. The Young's modulus is smallest along the [010] direction and largest along the [111] direction (see table 7): the anisotropy ratio ranges

Table 5. Elastic constants $\left(C_{i j}\right)$ and bulk modulus $(B)$ (in GPa) of MnP systems.

\begin{tabular}{|c|c|c|c|c|c|c|c|c|c|c|c|}
\hline & & $C_{11}$ & $C_{22}$ & $C_{33}$ & $C_{44}$ & $C_{55}$ & $C_{66}$ & $C_{12}$ & $C_{13}$ & $C_{23}$ & $B_{v}$ \\
\hline $\mathrm{NiSi}$ & [3] & 272 & 222 & 229 & 106 & 128 & 126 & 166 & 94 & 149 & 171 \\
\hline $\mathrm{PdSi}$ & & 228 & 167 & 230 & 77 & 90 & 75 & 126 & 104 & 142 & 152 \\
\hline \multirow[t]{2}{*}{ PtSi } & & 259 & 240 & 274 & 88 & 89 & 50 & 136 & 101 & 136 & 169 \\
\hline & [12] & 298 & 269 & 308 & 100 & 104 & 66 & 156 & 132 & 165 & 198 \\
\hline $\mathrm{NiGe}$ & & 193 & 16 & 172 & 71 & 102 & 104 & 136 & 92 & 116 & 136 \\
\hline PdGe & & 179 & 139 & 175 & 60 & 74 & 69 & 112 & 87 & 110 & 124 \\
\hline PtGe & & 202 & 192 & 199 & 68 & 73 & 53 & 124 & 102 & 112 & 141 \\
\hline
\end{tabular}


Table 6. Isotropic values of the shear and bulk moduli (in GPa) using the Voigt, Reuss and Hill approximations (which are labeled as $V, R$, and $H$, respectively); Young's modulus (in GPa), the Poisson's ratio ( $v$ ) and the bulk modulus (in GPa) along the crystallographic axes $a, b$ and $c$ (see [14], appendix) are also provided.

\begin{tabular}{|c|c|c|c|c|c|c|c|c|c|c|c|c|}
\hline & & $G_{R}$ & $G_{V}$ & $G_{H}$ & $B_{R}$ & $B_{V}$ & $B_{H}$ & $E$ & $v$ & $B_{a}$ & $B_{b}$ & $B_{c}$ \\
\hline $\mathrm{NiSi}$ & [3] & 65 & 93 & 79 & 168 & 171 & 170 & 205 & 0.30 & 486 & 957 & 352 \\
\hline $\mathrm{PdSi}$ & & 50 & 65 & 57 & 150 & 152 & 151 & 153 & 0.33 & 532 & 298 & 702 \\
\hline \multirow[t]{2}{*}{$\mathrm{PtSi}$} & & 67 & 72 & 69 & 169 & 169 & 169 & 183 & 0.32 & 469 & 537 & 517 \\
\hline & [12] & 77 & 82 & 80 & 198 & 198 & 198 & 211 & 0.32 & 572 & 575 & 639 \\
\hline $\mathrm{NiGe}$ & & 68 & 68 & 56 & 134 & 136 & 135 & 147 & 0.32 & 419 & 605 & 292 \\
\hline PdGe & & 39 & 53 & 46 & 123 & 124 & 124 & 122 & 0.33 & 455 & 283 & 418 \\
\hline $\mathrm{PtGe}$ & & 56 & 56 & 54 & 141 & 141 & 141 & 144 & 0.33 & 445 & 449 & 381 \\
\hline
\end{tabular}
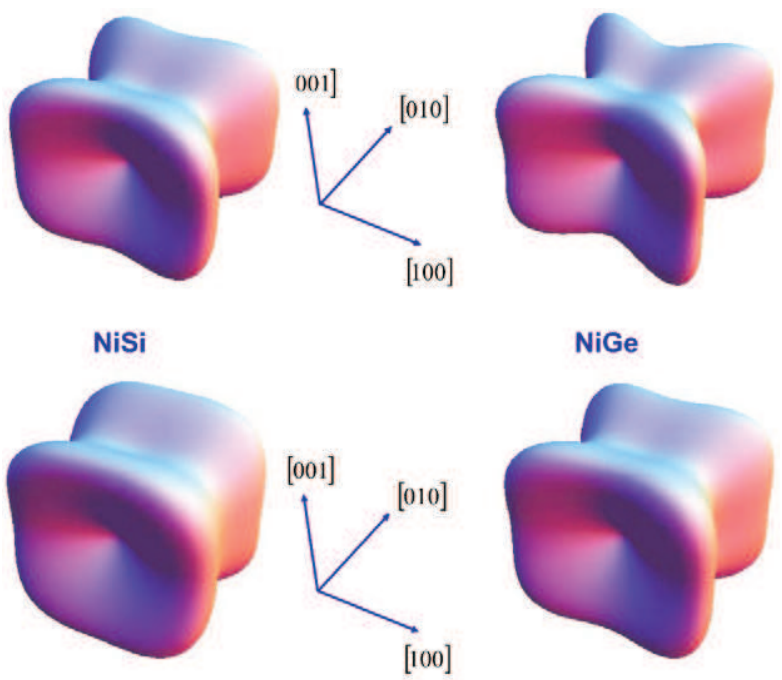

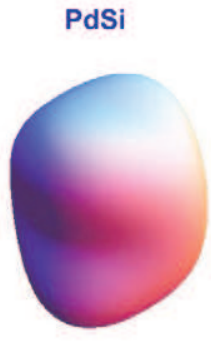

PtSi
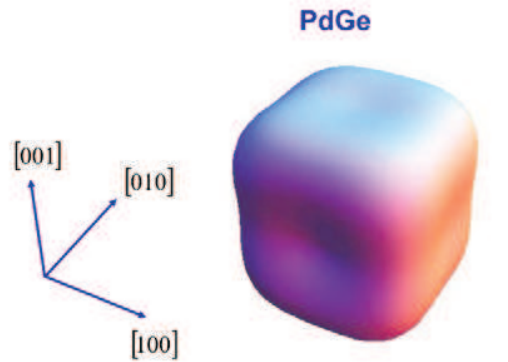

PtGe
Figure 3. 3D representations of the Young's modulus.

from 1.5 to 3.5 , depending on the composition. Analysis on the anisotropy in the shear factors (see table 8) results in the same conclusion.

All of these results suggest that the anisotropy is controlled mainly by the nature of the metal.

We conclude our analysis of the anisotropy in $\mathrm{MnP}$ systems with a discussion of the Poisson's ratio, $v$. In cubic systems, $v$ lies within the range $\left[-1, \frac{1}{2}\right]$. However, many studies have shown (see for example [15]) that the Poisson's ratio in non-cubic systems is not bounded from either above or below. In the appendix, we present the equations for computing the Poisson's ratio in a direction (m) perpendicular to a different stress direction (n). In table 9, we report $v_{\mathbf{n}}^{\mathbf{m}}$, where $\mathbf{m}$ and $\mathbf{n}$ are along the main directions ( $x, y$ and $z$ ).
Table 7. Young's modulus (in GPa) along different crystallographic directions.

\begin{tabular}{|c|c|c|c|c|c|c|}
\hline & & $E_{100}$ & $E_{010}$ & $E_{001}$ & $E_{111}$ & $E_{111} / E_{010}$ \\
\hline $\mathrm{NiSi}$ & [3] & 146 & 78 & 127 & 235 & 3.0 \\
\hline $\mathrm{PdSi}$ & & 133 & 58 & 109 & 183 & 3.1 \\
\hline \multirow[t]{2}{*}{ PtSi } & & 179 & 140 & 194 & 193 & 1.4 \\
\hline & [12] & 201 & 150 & 200 & 226 & 1.5 \\
\hline $\mathrm{NiGe}$ & & 83 & 51 & 91 & 177 & 3.5 \\
\hline PdGe & & 88 & 45 & 88 & 146 & 3.2 \\
\hline PtGe & & 115 & 100 & 127 & 164 & 1.6 \\
\hline
\end{tabular}

Table 8. The anisotropy in the shear elastic factor $\left(A_{i}\right.$, where $i=1,2,3)$, the anisotropy in the directional bulk modulus $\left(A_{B_{a}}, A_{B_{C}}\right)$ and the anisotropy in the compressibility and the shear modulus $\left(A_{B}\right.$ and $A_{G}$ in $\left.\%\right)$.

\begin{tabular}{|c|c|c|c|c|c|c|c|}
\hline & $A_{1}$ & $A_{2}$ & $A_{3}$ & $A_{B_{a}}$ & $A_{B_{c}}$ & $A_{B}$ & $A_{G}$ \\
\hline $\mathrm{NiSi}$ & 1.35 & 3.37 & 3.13 & 0.51 & 0.37 & 1.0 & 17.7 \\
\hline $\mathrm{PdSi}$ & 1.23 & 3.19 & 2.10 & 1.78 & 2.36 & 0.6 & 13.6 \\
\hline $\mathrm{PtSi}$ & 1.06 & 1.47 & 0.87 & 0.87 & 0.96 & 0.04 & 3.6 \\
\hline $\mathrm{NiGe}$ & 1.5 & 3.8 & 4.6 & 0.6 & 0.4 & 0. & 22.5 \\
\hline PdGe & 1.34 & 3.18 & 2.96 & 1.60 & 1.47 & 0.2 & 15.5 \\
\hline PtGe & 1.39 & 1.75 & 1.44 & 0.99 & 0.85 & 0.06 & 3.3 \\
\hline
\end{tabular}

The elastic behavior observed under a uniaxial strain is clearly different from the elastic behavior of cubic systems. In some cases, the value of $v$ is larger than 0.5 (as in $v_{1,0,0}^{0,1,0}$, for example). Moreover, when the system is stressed along $\mathbf{n}=a$ (or $c$ ), a strong contraction $\left(v_{1,0,0}^{0,1,0}>0.5\right)$ is observed along the $b$ direction, whereas the system expands slightly $\left(v_{1,0,0}^{0,0,1}<0\right)$ along the $c$ axis for $\mathrm{NiSi}, \mathrm{PdSi}, \mathrm{NiGe}$ and PdGe. These results may be correlated with the thermal expansion of the lattice parameters: the $b$ axis contracts and the $a$ and $c$ axes expand over the temperature range between 293 and $700 \mathrm{~K}[11,16]$ for these systems; however, a clear explanation is not yet available.

\section{Effect of the composition on the elastic properties in $\mathrm{NiSi}_{1-x} \mathbf{G e}_{x}$}

In this section, the effect of the composition on the elastic properties of $\mathrm{NiSi}_{1-x} \mathrm{Ge}_{x}$ alloys is presented. Variations in the Ge content in NiX systems and intermediate compositions 
Table 9. Anisotropy in the Poisson's ratio, $v_{\mathbf{n}}^{\mathbf{m}}$, for $\mathbf{m}$ and $\mathbf{n}$ along the $\{x, y, z\}$ axes.

\begin{tabular}{llrllrl}
\hline & $v_{1,0,0}^{0,1,0}$ & $v_{1,0,0}^{0,0,1}$ & $v_{0,1,0}^{1,0,0}$ & $v_{0,1,0}^{0,0,1}$ & $v_{0,0,1}^{1,0,0}$ & $v_{0,0,1}^{0,1,0}$ \\
\hline NiSi & 0.84 & -0.14 & 0.45 & 0.47 & -0.12 & 0.76 \\
PdSi & 0.78 & -0.03 & 0.34 & 0.46 & -0.02 & 0.87 \\
PtSi & 0.50 & 0.12 & 0.39 & 0.35 & 0.13 & 0.49 \\
\hline NiGe & 0.83 & -0.03 & 0.51 & 0.41 & -0.04 & 0.72 \\
PdGe & 0.83 & -0.02 & 0.42 & 0.42 & -0.02 & 0.81 \\
PtGe & 0.51 & 0.23 & 0.45 & 0.33 & 0.25 & 0.42 \\
\hline
\end{tabular}

Table 10. Lattice parameters (in $\AA$ ), volume $\left(V_{o}\right.$, in $\left.\AA^{3}\right)$, and formation energies $\left(E_{\mathrm{f}}\right.$, in $\mathrm{meV} /$ atom $)$ of $\mathrm{NiSi}_{1-x} \mathrm{Ge}_{x}$ systems, for various values of the Ge content $x$.

\begin{tabular}{lclllr}
\hline$x$ & $E_{\mathrm{f}}$ & $a_{o}$ & $b_{o}$ & $c_{o}$ & $V_{o}$ \\
\hline 0 & -503 & 5.165 & 3.378 & 5.621 & 98 \\
0.25 & -446 & 5.247 & 3.376 & 5.700 & 101 \\
0.50 & -400 & 5.346 & 3.393 & 5.742 & 104 \\
0.75 & -353 & 5.358 & 3.435 & 5.806 & 107 \\
1 & -313 & 5.419 & 3.464 & 5.864 & 110 \\
\hline
\end{tabular}

were studied further by sequentially replacing a $\mathrm{Si}$ atom by a Ge atom.

Ground state properties. Calculations were performed on a primitive cell (eight atoms), and all of the configurations (at each Ge content) were used to evaluate the effect of the composition on the ground state properties. Equivalent results were obtained for each configuration studied at a given Ge content (the difference in energies and lattice parameters is negligible); therefore we only list the results (the lattice parameters and the formation energies) for one configuration in table 10. Substituting $\mathrm{Si}$ with Ge induces a monotonic change in the energy. To illustrate this result, we use a linear regression to fit the formation energy as a function of the $\mathrm{Ge}$ content $(x$, in \%). We obtain the following expression (with a correlation factor of $R^{2}=1$ ):

$$
E_{\mathrm{f}}(x)=-497+189 x .
$$

An equivalent relation can be found for the evolution of the volume. We find that the volume of the cell increases linearly with the Ge content: $\sim 98+12 x$ (in $\AA^{3}$ ).

To confirm these results, we investigate the ground state properties for larger supercells. Intermediate $\mathrm{Ge}(\mathrm{Si})$ contents, i.e., $\mathrm{Ni}_{32} \mathrm{Si}_{x} \mathrm{Ge}_{32-x}$, are simulated using $2 \times 2 \times 2$ supercells. For $x$ ranging from 0 to 32 , we consider only one configuration (the inter-atomic forces and the stresses on boxes are also

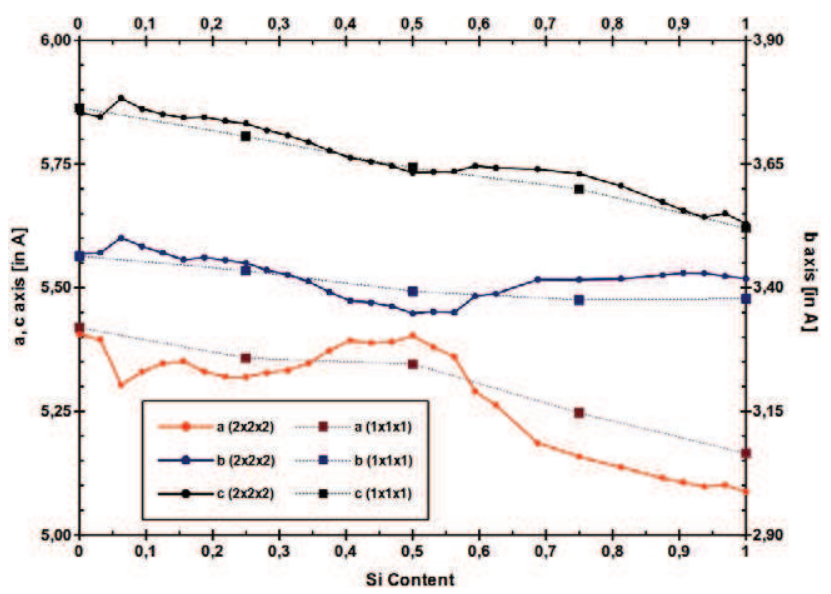

Figure 4. Evolution of the lattice parameters in $\mathrm{NiSi}_{x} \mathrm{Ge}_{1-x}$ systems as a function of $x$; the dashed lines represent data computed using a primitive cell, and the lines represent data for the lattice parameters computed using $2 \times 2 \times 2$ supercells.

fully relaxed). The orthorhombic symmetries of the supercells are almost completely preserved in the final structures, which exhibit a low crystalline anisotropy (i.e., less than $10^{-4}$ ) even at intermediate $\mathrm{Ge}(\mathrm{Si})$ contents. The evolutions of the formation energies and the volumes with the Ge content are found to be equivalent using the primitive cell and the supercell. Figure 4 shows that the lattice parameters do not evolve monotonically, despite the overall increase in the lattice parameters for the systems containing Si. These results confirm that the evolution of the lattice parameters is mainly controlled by steric effects.

Evolution of elasticity for systems containing Ge. Our results for the ground state properties suggest that the elastic properties of these systems should change monotonically with the Ge content. We computed the elastic constants for three intermediate $\mathrm{Ge}$ contents using the primitive cell (corresponding to one configuration for each content value). Table 11 shows the results of these simulations $\left(C_{i j}\right)$. Figure 5 shows the evolution of these elastic constants. The elastic constants clearly evolve linearly with $x$. Within a first-order approximation, the properties of $\mathrm{MSiGe}$ alloy (where $\mathrm{M}=\mathrm{Pt}$ or Pd) structures can be interpolated linearly from extreme systems (NiSi and $\mathrm{NiGe})$.

\section{Conclusion}

In this study, we have presented first-principles calculations of the ground states $(\mathrm{X}=\mathrm{Si}$ or $\mathrm{Ge}$, and $\mathrm{M}=\mathrm{Ni}, \mathrm{Pd}$ or

Table 11. Evolution of the elastic constants (in GPa) with the Ge content in $\mathrm{NiGe}_{x} \mathrm{Si}_{1-x}$.

\begin{tabular}{llllrllllll}
\hline$x$ & $C_{11}$ & $C_{22}$ & $C_{33}$ & $C_{44}$ & $C_{55}$ & $C_{66}$ & $C_{12}$ & $C_{13}$ & $C_{23}$ & $B_{v}$ \\
\hline 0 & 272 & 222 & 229 & 106 & 128 & 126 & 147 & 94 & 149 & 171 \\
0.25 & 248 & 202 & 218 & 95 & 123 & 120 & 153 & 85 & 138 & 158 \\
0.50 & 222 & 186 & 201 & 88 & 114 & 113 & 149 & 97 & 134 & 152 \\
0.75 & 208 & 179 & 188 & 79 & 109 & 111 & 144 & 98 & 127 & 146 \\
1 & 193 & 167 & 172 & 71 & 102 & 104 & 136 & 92 & 116 & 136 \\
\hline
\end{tabular}




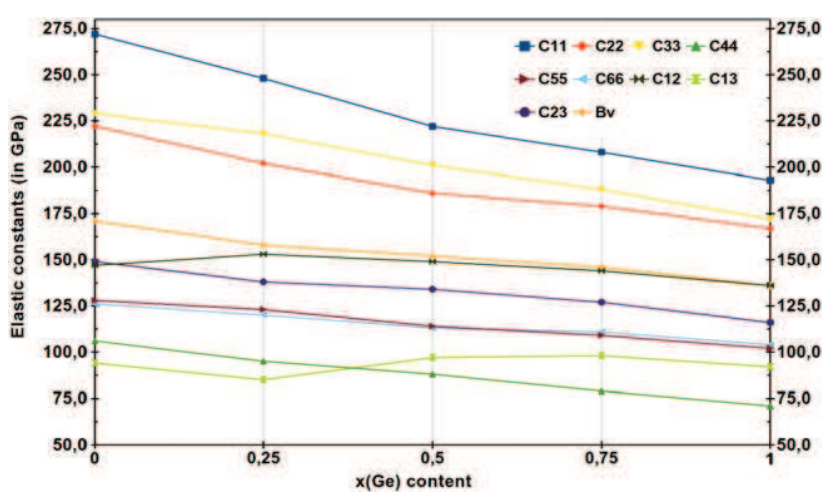

Figure 5. Evolution of the elastic constants with the Ge content

$\mathrm{Pt}$ ) of MX-MnP structures. The structural, electronic and elastic properties of ideal structures were calculated using density functional theory. We showed that the main structural differences between $\mathrm{Si}$ and $\mathrm{Ge}$ systems can be attributed to steric effects. These systems exhibit a strong elastic anisotropy, which fades upon changing the metal species from $\mathrm{Ni}$ to $\mathrm{Pt}$.

To illustrate these steric effects, we performed simulations on $\mathrm{NiSi}_{1-x} \mathrm{Ge}_{x}$ alloys. We showed that the properties of these alloys can be satisfactorily linearly interpolated based on the Ge content. We propose that these results can be extrapolated to Pt and Pd alloys.

\section{Acknowledgments}

This work was granted access to the HPC resources of CALMIP (CICT Toulouse, France) under the allocation 2012-p0912.

\section{Appendix. Anisotropy in Poisson's ratio}

In general, Poisson's ratio ( $v$ ) in non-cubic systems is considered to be an 'average' value, which is computed as follows:

$$
v=\frac{3 B-2 G}{2(3 B+G)} .
$$

However, $v$ depends on the transverse contraction under the application of a uniaxial stress. Boulanger et al [17] have shown that Poisson's ratio $\left(v=v_{\mathbf{n}}^{\mathbf{m}}\right)$ depends on the direction $\mathbf{n}$ of the applied tension and $\mathbf{m}$, which is orthogonal to $\mathbf{n}$. We can calculate Poisson's ratio for the application of a stress along the $x, y$ or $z$ axis in orthorhombic systems as follows:

$$
\begin{gathered}
v_{1,0,0}^{0, \cos \theta, \sin \theta}=\frac{C_{12} C_{33}-C_{13} C_{23}}{C_{22} C_{33}-C_{23}^{2}} \cos ^{2} \theta \\
+\frac{C_{13} C_{22}-C_{12} C_{23}}{C_{33} C_{22}-C_{23}^{2}} \sin ^{2} \theta \\
v_{0,1,0}^{\sin \theta, 0, \cos \theta}=\frac{C_{23} C_{11}-C_{12} C_{13}}{C_{33} C_{11}-C_{13}^{2}} \cos ^{2} \theta \\
+\frac{C_{12} C_{33}-C_{23} C_{13}}{C_{11} C_{33}-C_{13}^{2}} \sin ^{2} \theta \\
v_{0,0,1}^{\cos \theta, \sin \theta, 0}=\frac{C_{13} C_{22}-C_{12} C_{23}}{C_{11} C_{22}-C_{12}^{2}} \cos ^{2} \theta \\
+\frac{C_{23} C_{11}-C_{12} C_{13}}{C_{11} C_{22}-C_{12}^{2}} \sin ^{2} \theta
\end{gathered}
$$

where $\theta$ represents the direction of $\mathbf{m}$ in the plane perpendicular to $\mathbf{n}$, i.e., $\mathbf{m}=(0, \cos \theta, \sin \theta)$.

\section{References}

[1] Thompson S E et al 2004 IEEE Electron Device Lett. 25191

[2] Patton G L, Iyer S S, Delage S L, Tiwari S and Stork J M C 1988 IEEE Electron Device Lett. 9165

[3] Connétable D and Thomas O 2009 Phys. Rev. B 79094101

[4] Vocadlo L, Wood I G and Dobson D P 2012 J. Appl. Crystallogr. 45 186-96

[5] Kresse G and Hafner J 1993 Phys. Rev. B 47558

Kresse G and Hafner J 1994 Phys. Rev. B 4914251

Kresse G and Furthmüller J 1996 Phys. Rev. B 5411169

Kresse G and Furthmüller J 1996 Comput. Mater. Sci. 615

[6] Kresse G and Joubert D 1999 Phys. Rev. B 591758

[7] Perdew J P, Burke K and Ernzerhof M 1996 Phys. Rev. Lett. 773865

Perdew J P, Burke K and Ernzerhof M 1997 Phys. Rev. Lett. 781396

[8] Monkhorst H J and Pack J D 1976 Phys. Rev. B 135188

[9] Kittel C 1996 Introduction to Solid State Physics (New York: Wiley)

[10] Chepulskii R V, Barabash S V and Zunger A 2012 Phys. Rev. B 85144201

[11] Brondeel L and Detavernier C 2009 Report on 'In situ' XRD thermische expansie van materialen

[12] Beckstein O, Klepeis J E, Hart G L W and Pankratov O 2001 Phys. Rev. B 63134112

[13] Chandrasekharaiah M S, Margrave J L and O'Hare P A G 1993 J. Phys. Chem. Ref. Data 221459

[14] Ravindran P, Fast L, Korzhavyi P A, Johansson B, Wills J and Eriksson O 1998 J. Appl. Phys. 844891

[15] Ting T C T and Chen T Y 2005 Q. J. Mech. Appl. Math. $\mathbf{5 8} 73-82$

[16] Wilson D F and Cavin O B 1992 Scr. Metall. Mater. 268

[17] Boulanger P H and Hayes M 1998 J. Elasticity 50 87-9 